\title{
Cuttings Transport Models and Experimental Visualization of Underbalanced Horizontal Drilling
}

\author{
Na Wei, ${ }^{1}$ YingFeng Meng, ${ }^{1}$ Gao Li, ${ }^{1}$ LiPing Wan, ${ }^{1}$ ZhaoYang Xu, \\ XiaoFeng $\mathrm{Xu},{ }^{2}$ and YuRui Zhang ${ }^{1}$ \\ ${ }^{1}$ State Key Laboratory of Oil and Gas Geology and Exploration, Southwest Petroleum University, Chengdu 610500, China \\ ${ }^{2}$ Drilling and Production Technology Institute, PetroChina Jidong Oilfield Company, Tangshan 063004, China
}

Correspondence should be addressed to YingFeng Meng; cwctmyf@vip.sina.com

Received 11 April 2013; Revised 22 June 2013; Accepted 25 June 2013

Academic Editor: Guo-Cheng Wu

Copyright (C) $2013 \mathrm{Na}$ Wei et al. This is an open access article distributed under the Creative Commons Attribution License, which permits unrestricted use, distribution, and reproduction in any medium, provided the original work is properly cited.

Aerated underbalanced horizontal drilling technology has become the focus of the drilling industry at home and abroad, and one of the engineering core issues is the horizontal borehole cleaning. Therefore, calculating the minimum injection volume of gas and liquid accurately is essential for the construction in aerated underbalanced horizontal drilling. This paper establishes a physical model of carrying cuttings and borehole cleaning in wellbore of horizontal well and a critical transport mathematical model according to gas-liquid-solid flow mechanism and large plane dunes particle transport theory.

\section{Introduction}

With the development of horizontal drilling oriented technology and thin formation of oil and gas reservoirs, aerated underbalanced horizontal drilling technology has become the focus of the drilling industry at home and abroad, and one of the engineering core issues is the horizontal borehole cleaning when gas-bearing mud exists [1-3]. Therefore, calculating the minimum injection volume of gas and liquid accurately is essential for the construction in aerated underbalanced horizontal drilling. To calculate the required minimum injection volume of gas and liquid accurately which can safely carry cuttings, it is necessary to carry out the researches of carrying cuttings theory and visualization experiment of particle motion in depth.

\section{Transport Law Analysis of Cuttings in the Horizontal Wellbore}

2.1. Particularity of Cuttings Transport in Horizontal Well. The cuttings' distributions in horizontal section and vertical section are shown in Figures 1 and 2. When the rock is broken by bit, the large particle cuttings can transport smoothly at drill collar because of the high flow rate, but when they reach the drill collar and drill pipe junction large particle cuttings are accumulated due to the annulus area sudden increase. Contrasting vertical section and horizontal section $[4,5]$, we can find that in vertical section the larger cuttings will fall to the bottom of the well then be repeatedly broken, but in horizontal section once the large cuttings are produced which the fluid cannot carry, these cuttings will only stay at the lower side of the wall waiting for drill tool rolling until forming small particles to be carried by fluid to downstream.

2.2. Horizontal Well Cuttings Movement Form. In horizontal well cuttings transportation can be divided into suspension, rolling, and saltation.

2.2.1. Suspension. Suspension is an important way of cuttings movement. The form of the suspension is drift with drilling fluid. In suspension there are two kinds of force, one is gravity which makes cuttings settle down to the lower side of the wall and another kind is gas-liquid two-phase flow driving force which makes cuttings particle move to downstream along the wellbore. The speed of cuttings moving to downstream is related to the speed of gas-liquid two-phase flow, 


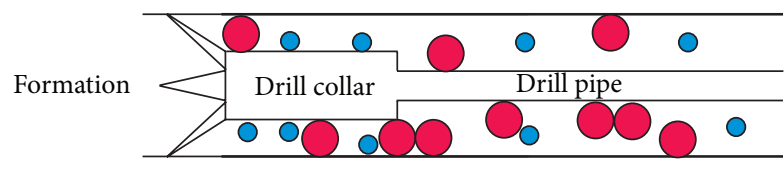

FIGURE 1: Cuttings distribution in horizontal section.

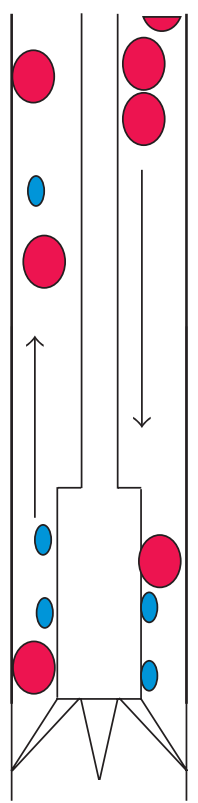

FIGURE 2: Cuttings distribution in vertical section.

the transportation volume of cuttings can indirectly represent the speed of cuttings moving to downstream, and the greater the flow, the more it carried cuttings. In settling process suspended particles are brought back to the top by eddy current that makes the cuttings drift up and down. As a result, the settling velocity becomes slow. Suspension of cuttings schematic diagram is shown in Figure 3.

2.2.2. Rolling. When flow drag force is greater than particle resistance, the particles located in the surface outstanding position of cuttings bed begin to move in the form of slipping. Because of the rough wall surface, slipping often converts into rolling and the cuttings always keep contact with the lower side of the wall, the force as shown in Figure 4 and cuttings rolling schematic diagram as shown in Figure 5.

2.2.3. Saltation. When the jumping cuttings fall to the lower side of the wall, it will impact the cuttings bed, and the force is related to the jump height and drilling fluid velocity [68]. If the cuttings jump low, the momentum obtained from the fluid is small and they will stop jumping. If not, they will jump again. The jumping height is inversely proportional to the drilling fluid density. This special movement is called saltation, cuttings saltation force as shown in Figure 6.

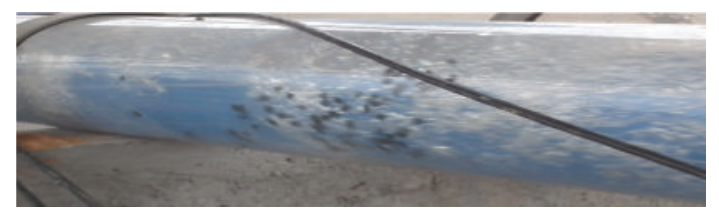

FIGURE 3: Cuttings suspension diagram in multiphase flow condition.

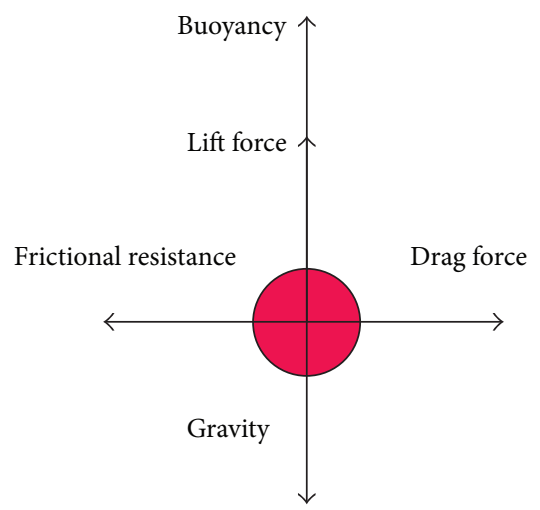

FIGURE 4: Cuttings rolling force in horizontal well.

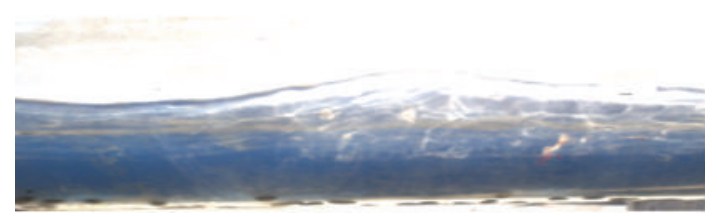

FIGURE 5: Cuttings rolling schematic diagram in horizontal well.

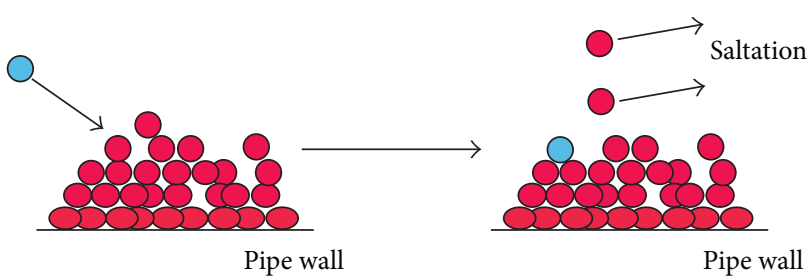

FIGURE 6: Cuttings saltation schematic diagram in horizontal section.

\section{Carrying Cuttings Model of Multiphase Flow in Horizontal Well Annulus}

3.1. Cuttings Rolling. When cuttings are based on single particle rolling on the lower side of the wall, with the effect of the gas-liquid two-phase flow, they transport to the downstream [9].

3.1.1. Cuttings Particle Rolling Force Analysis. When the gasliquid flow rate is small, the particles first roll in single in the wall, and the forces include: drag force $F_{D}$ produced by air current, friction force $F_{\text {friction }}$ along the contact surface between the particle and the wall, gravity $G$, buoyancy 


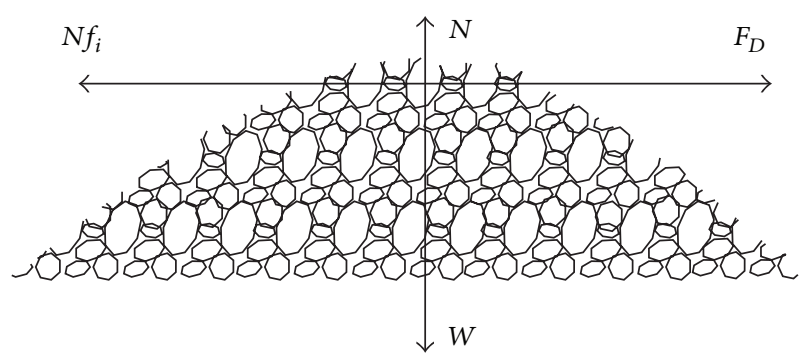

Figure 7: The force analysis of cuttings accumulation.

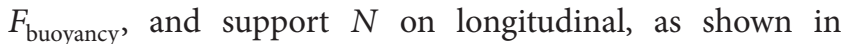
Figure 4.

3.1.2. Cuttings Particle Rolling Starting Condition. It is necessary to build a horizontal mathematical equation to determine the minimum gas liquid volume when single particle cuttings roll forward [10]:

$$
\begin{gathered}
C_{D} \frac{\rho_{m} v_{m}^{2}}{2} \frac{\pi d_{s}^{2}}{4}=k G, \\
v_{m}=\frac{q_{l}+q_{g}}{A},
\end{gathered}
$$

where $C_{D}$ is resistance coefficient, dimensionless; $\rho_{m}$ is fluid density, $\mathrm{kg} / \mathrm{m}^{3} ; v_{m}$ is fluid velocity, $\mathrm{m} / \mathrm{s} ; d_{s}$ is cuttings particle diameter, $\mathrm{m} ; k$ is friction resistance coefficient, dimensionless; $G$ is cuttings particle gravity, $\mathrm{N} ; q_{l}$ is liquid phase flow rate, $\mathrm{m}^{3} / \mathrm{s} ; q_{g}$ is gas phase flow rate, $\mathrm{m}^{3} / \mathrm{s} ; A$ is flow area, $\mathrm{m}^{2}$.

The minimum velocity $v_{m}$ can be derived from the different particle gravity $G$ and different materials friction resistance coefficient $k$.

\subsection{Cuttings Saltation}

3.2.1. Cuttings Particle Rolling Force Analysis. When cuttings transport in the annulus, the forces mainly include gravity, resistance, the saffman lift force, buoyancy, basset force, pressure gradient force, added mass force and magnus effect force in underbalanced drilling [11, 12]; force analysis is as shown in Figure 7. In the horizontal section, cuttings gravity is the main force to constitute horizontal friction resistance, and the calculation formula is

$$
W=\rho_{s} V_{s} g,
$$

where $W$ is cuttings particle gravity, $\mathrm{N} ; \rho_{s}$ is cuttings particle density, $\mathrm{kg} / \mathrm{m}^{3} ; V_{s}$ is cuttings particle volume, $\mathrm{m}^{3} ; g$ is gravity acceleration coefficient, $\mathrm{m} / \mathrm{s}^{2}$.

The driving force of the cuttings is mainly gas-liquid two-phase dragging force. The dragging force is influenced by many factors like the Reynolds number, cuttings size, cuttings shape, flow state, and fluid compressibility $[13,14]$. Its direction is consistent with the speed of fluid relative to the particles, and the calculation formula is

$$
F_{D}=C_{D} \frac{\rho_{m}\left(v_{m}-v_{s}\right)^{2}}{2} \frac{\pi d_{s}^{2}}{4},
$$

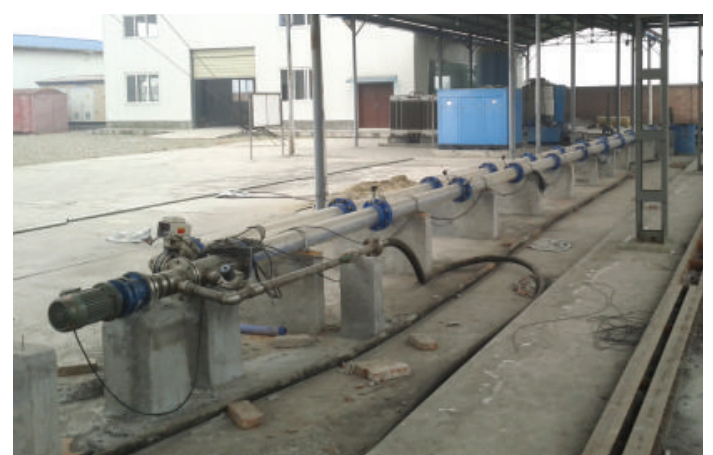

FIGURE 8: Horizontal experiment facilities.

where $F_{D}$ is dragging force, $\mathrm{N} ; C_{D}$ is dragging coefficient, dimensionless; $v_{m}$ is fluid velocity, $\mathrm{m} / \mathrm{s} ; v_{s}$ is cuttings particle transport velocity, $\mathrm{m} / \mathrm{s} ; d_{s}$ is cuttings particle diameter, $\mathrm{m}$.

3.2.2. Cuttings Particle Rolling Starting Condition. Cuttings particle group located in cuttings bed and flow boundary presents a state of bulk material accumulation [15]. The bulk materials limit equilibrium equation of cuttings particles can be signified as follows:

$$
T_{\lim }=N f_{i}+F A,
$$

where $T_{\lim }$ is the ultimate shear force making the particle moves, $\mathrm{N} ; \mathrm{N}$ is internal force effecting on the particle, $\mathrm{N} ; f_{i}$ is internal friction coefficient of bulk material accumulation, dimensionless; $F$ is unit cohesion, $\mathrm{N} / \mathrm{m}^{2} ; A$ is flow area, $\mathrm{m}^{2}$.

According to the force analysis of cuttings particles as shown in Figure 8, ignoring cohesive force and buoyancy [16], the accumulation particles limit force balance equation can be deformed into

$$
F_{D}=f_{i} W
$$

where $T_{\text {lim }}=F_{D}, N=W$.

$f_{i}$ can be determined by experiment. In general, $f_{i}$ is of particle group $\varepsilon$, given as

$$
f_{i}=\mu_{i}+\frac{\alpha / \beta}{e^{\alpha(\varepsilon-0.26)}-1+\alpha / \beta},
$$

where $\varepsilon$ is void fraction of particle group, dimensionless; $\alpha, \beta$ is parameters related to cuttings accumulation degree, dimensionless; $\mu_{i}$ is internal friction coefficient of particles, dimensionless.

When saltation starts, force balance formula can be derived by combining formula (2), (3), and (6) as follows:

$$
C_{D} \frac{\rho_{m} v_{m}^{2} \pi d_{s}^{2}}{8}=\left[\mu_{i}+\frac{\alpha / \beta}{e^{\alpha(\varepsilon-0.26)}-1+\alpha / \beta}\right] \frac{\pi d_{s}^{3}}{6} \rho_{s} g
$$

where $v_{m}$ is fluid flow velocity under granular limit balance state; when $v_{m}$ continues to increase, the balance will be broken and cuttings will begin to transport, $\mathrm{m} / \mathrm{s}$. 


\section{The Visualization Experiment of Horizontal Section}

This study establishes an annulus visualization organic glass experimental facility (total length $25 \mathrm{~m}$, experimental annulus outer tube and inner diameter $140 \mathrm{~mm}$, inner tube outer diameter $63 \mathrm{~mm}$, inner tube inner diameter $55 \mathrm{~mm}$ ), which uses compressed air and water as experiment flow and simulation cuttings (equivalent diameter $6 \mathrm{~mm}$ ) as experiment medium, developing critical carrying cuttings in different liquid injections and tests the hydrodynamic parameters. Then we can get borehole cleaning critical carrying cuttings data in different experiment conditions.

\subsection{Experiment Research Content}

(1) Simulation of multiphase flow and carrying cuttings large bench in horizontal section (simulation of the rotating drill pipe in rotary drilling)

(2) Simulation of multiphase flow and carrying cuttings large bench in horizontal section (simulation of the slide drilling and circulation after stopping drilling).

4.2. Experimental Facilities. Experimental facilities which simulate air flow condition at certain range of pressure and flow rate down the hole include experimental bench, air compressor, gas tank, water tank, liquid pump, and flow meter, as shown in Figure 8. Experiment testing part is monitoring and recording pipe section pressure, gas flow rate, liquid flow rate, image of the phenomenon, and so forth.

4.3. Experiment Process. The simulation cuttings are injected in different speeds at the bottom, maintaining a certain amount of gas injection and then increasing the liquid injection (liquid injection can be controlled from $0 \sim 5 \mathrm{~L} / \mathrm{s}$ ) until the cuttings are suspended in the experiment pipe section; at this time the gas flow rate is considered as the critical flow rate. The liquid flow rate was ratcheted up after injecting the liquid for 2 minutes steadily, and the experiment was stopped until the cuttings of the bottom are carried out completely. The test parameters include liquid injection, gas injection, liquid flow velocity, cuttings velocity, and cuttings concentration. Flow pressure is controlled from $0.1 \mathrm{MPa}$ to $0.6 \mathrm{MPa}$ throughout the experiment.

\subsection{Experiment Phenomena}

(1) When the drill string is rotating, experiment phenomena are shown in Figures 9 and 10.

(2) When the drill is immovability, experiment phenomena are shown in Figures 11, 12, and 13.

Through the observation, comparing with the drill which is immovability, when the drill string is rotating it has a viscous impact on the surrounding drilling fluid due to its viscosity, and then cuttings on the cuttings bed are agitated, so the effect of carrying cuttings is better in conditions of

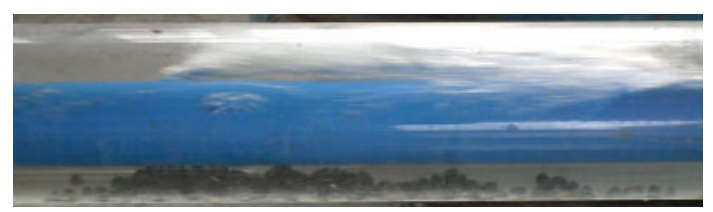

FIgURE 9: The formation of the cuttings bed.

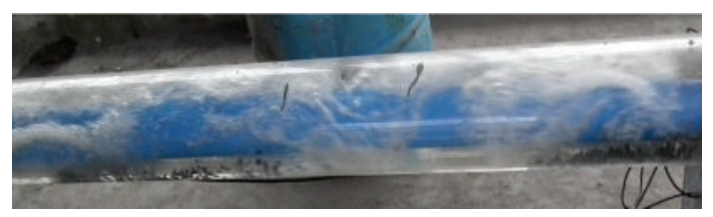

FIGURE 10: Cuttings transport.

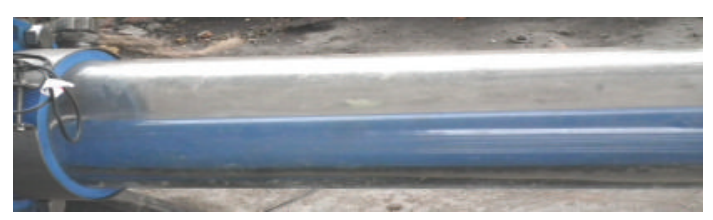

FIGURE 11: The drill is $100 \%$ eccentric.

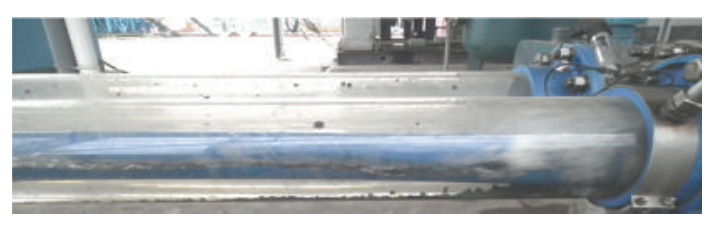

FIgURE 12: The formation of the cuttings bed.

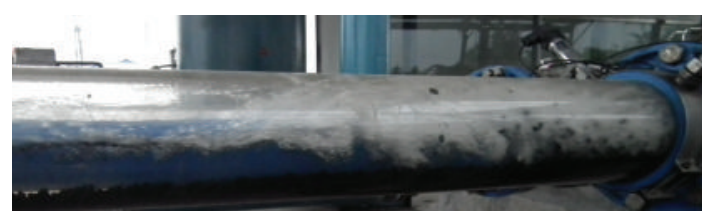

FIGURE 13: Cuttings transport.

injecting the same volume of gas. The way of cuttings transport is mainly saltation.

\subsection{Experimental Data and Processing Results}

(1) When the drill string is rotating, calculation results in different injecting volumes of gas and liquid (see Table 1).

(2) When the drill is immovability, calculation results in different injecting volumes of gas and liquid (see Table 2).

Through the previous experimental data and phenomena, comparing with the drill which is immovability, the drill rotating can make the water acts as the simulation drilling fluid moving in spirals and the pressure of annular flow field distributing in fluctuation forms. At the same time, when 
TABLE 1: Calculation results in different injecting volumes of gas and liquid (rotating).

\begin{tabular}{lcccc}
\hline Liquid injection $(\mathrm{l} / \mathrm{s})$ & $\begin{array}{c}\text { Gas injection } \\
\left(\mathrm{m}^{3} / \mathrm{h}\right)\end{array}$ & $\begin{array}{c}\text { Model mixing speed (bottom) } \\
(\mathrm{m} / \mathrm{s})\end{array}$ & $\begin{array}{c}\text { Critical mixing speed } \\
(\text { bottom })(\mathrm{m} / \mathrm{s})\end{array}$ & $\begin{array}{c}\text { Error between model } \\
\text { and real }(\%)\end{array}$ \\
\hline 0.87 & 65 & 0.72 & 1.05 & $45.9 \%$ \\
1.3 & 70 & 0.80 & 0.96 & $20.8 \%$ \\
1.86 & 90 & 1.04 & 1.32 & $26.8 \%$ \\
2.17 & 95 & 1.11 & 1.37 & 1.64 \\
2.6 & 120 & 1.40 & 1.73 & $17.5 \%$ \\
3.25 & 130 & 1.52 & & \\
\hline Average error & & & & $24.4 \%$ \\
\hline
\end{tabular}

In Table 1 the critical flow speed refers to the minimum mixing speed when cuttings start to saltate. In the condition attaining to the critical carrying cuttings, comparing the speed calculated by multiphase flow simulation software with the real mixing speed of gas-liquid two-phase flow, the error is concluded and then the current carrying cuttings model is amended.

TABLE 2: Calculation results in different injecting volumes of gas and liquid (immovability).

\begin{tabular}{lcccc}
\hline Liquid injection $(\mathrm{l} / \mathrm{s})$ & $\begin{array}{c}\text { Gas injection } \\
\left(\mathrm{m}^{3} / \mathrm{h}\right)\end{array}$ & $\begin{array}{c}\text { Model mixing speed (bottom) } \\
(\mathrm{m} / \mathrm{s})\end{array}$ & $\begin{array}{c}\text { Critical mixing speed } \\
\text { (bottom) }(\mathrm{m} / \mathrm{s})\end{array}$ & $\begin{array}{c}\text { Error between model } \\
\text { and real }(\%)\end{array}$ \\
\hline 0.87 & 90 & 0.99 & 1.29 & $30.2 \%$ \\
1.3 & 115 & 1.28 & 1.59 & $24.5 \%$ \\
1.86 & 130 & 1.46 & 1.73 & 1.91 \\
2.17 & 150 & 1.67 & 2.11 & $14.4 \%$ \\
2.6 & 170 & 1.88 & 2.28 & $12.5 \%$ \\
3.25 & 190 & 2.09 & & $9.3 \%$ \\
\hline Average error & & & & $18.3 \%$ \\
\hline
\end{tabular}

In Table 2 the critical flow speed refers to the minimum mixing speed when cuttings start to saltate. In the condition attaining to the critical carrying cuttings, comparing the speed calculated by multiphase flow simulation software with the real mixing speed of gas-liquid two-phase flow, the error is concluded and then the current carrying cuttings model is modified.

the drill string is rotating it will have a viscous impact on the surrounding drilling fluid due to its viscosity, and then cuttings on the cuttings bed are agitated, so the effect of carrying cuttings is better in conditions that injecting the same volume of gas.

\section{Model Modification}

5.1. Critical Carrying Cuttings Mathematical Model Modification in Horizontal Well (Rotation). From the result of experimental data, the real minimum continuous carrying cuttings comprehensive speed is the equal of $124 \%$ of saltation critical velocity as a modification model, given as

$$
v_{m}=1.24 \sqrt{\left[\mu_{i}+\frac{\alpha / \beta}{e^{\alpha(\varepsilon-0.26)}-1+\alpha / \beta}\right] \frac{4 d_{s}}{3 C_{D} \rho_{m}} \rho_{s} g}
$$

where $\tau_{i}=f_{i} \rho_{m}\left(v_{m}-v_{s}\right)^{2}$, stratified flow is $f_{i}=64 / N_{\mathrm{Re}}$, and turbulent (slug flow, agitation flow, and annular mist flow) is

$$
f_{i}=\left[1.14-2 \lg \left(\frac{e}{D}+\frac{21.25}{N_{\mathrm{Re}}^{0.9}}\right)\right]^{-2},
$$

where $\mu_{i}$ is internal friction coefficient of particles, dimensionless; $\alpha, \beta$ are parameters related to cuttings accumulation degree, dimensionless; $f_{i}$ is gas-liquid interface friction coefficient, dimensionless; $\tau_{i}$ is stress between mixture and wall shear, $\mathrm{Pa} ; \rho_{m}$ is mixture real density, $\mathrm{kg} / \mathrm{m}^{3} ; v_{m}$ is gas-liquid mixing velocity, $\mathrm{m} / \mathrm{s} ; C_{D}$ is drag coefficient, dimensionless, function of Re; $v_{s}$ is cuttings particle transport velocity, $\mathrm{m} / \mathrm{s}$; $d_{s}$ is cuttings particle diameter, $\mathrm{m} ; \rho_{s}$ is cuttings particle density, $\mathrm{kg} / \mathrm{m}^{3} ; N_{\mathrm{Re}}$ is the Reynolds number; $D$ is pipe diameter, $\mathrm{m}$.

5.2. Critical Carrying Cuttings Mathematical Model Modification in Horizontal Well (Immovability). From the result of experimental data, the real minimum continuous carrying cuttings comprehensive speed is the equal of $124 \%$ of saltation critical velocity as a modification model when the drill is rotating, namely,

$$
\begin{aligned}
v_{m} & =1.18 * 1.24 \sqrt{\left[\mu_{i}+\frac{\alpha / \beta}{e^{\alpha(\varepsilon-0.26)}-1+\alpha / \beta}\right] \frac{4 d_{s}}{3 C_{D} \rho_{m}} \rho_{s} g} \\
& =1.46 \sqrt{\left[\mu_{i}+\frac{\alpha / \beta}{e^{\alpha(\varepsilon-0.26)}-1+\alpha / \beta}\right] \frac{4 d_{s}}{3 C_{D} \rho_{m}} \rho_{s} g}
\end{aligned}
$$

where $\tau_{i}=f_{i} \rho_{m}\left(v_{m}-v_{s}\right)^{2}$, stratified flow is $f_{i}=64 / N_{\mathrm{Re}}$, and turbulent (slug flow, agitation flow, and annular mist flow) is

$$
f_{i}=\left[1.14-2 \lg \left(\frac{e}{D}+\frac{21.25}{N_{\mathrm{Re}}^{0.9}}\right)\right]^{-2} \text {. }
$$




\section{Conclusions}

(1) Comparing vertical section and horizontal section, in vertical section the larger cuttings will fall to the bottom of the well repeatedly broken, but in horizontal section once the large particle cuttings are produced which the fluid cannot carry, these cuttings will only stay at the lower side of the wall waiting for drill tool rolling until forming small particles to be carried by fluid to downstream.

(2) In horizontal section cuttings transport depending on gas-liquid comprehensive velocity and drilling fluid viscosity is mainly saltation, and the drill rotation benefits cuttings transport. In the condition of carrying cuttings smoothly, when the drill is immovability the comprehensive velocity is 1.18 times as big as when it is rotating. After processing the experimental data, the established mathematic model is modified.

\section{Acknowledgments}

The authors are grateful for the support of Open Fund of State Key Laboratory of Oil and Gas Geology and Exploration, Southwest Petroleum University (Transient flow behavior of the wellbore under condition of circulation cease in MPD, Grant no. PLN1309), National Natural Science Foundation of China (The wellbore flow model of liquid-based whole process underbalanced drilling, Grant no. 51204140, Formation evaluation theory research based on monitoring while underbalanced drilling, Grant no. 51104124 and Basic research on gas drilling, Grant no. 51134004), the Major State Science and Technology Special Project of China (Narrow density window of drilling technology and supporting equipment safety, Grant no. 2011ZX05021-003), National 973 Project of China (Safe and efficient drilling deep complex formation of basic research, Grant no. 2010CB226700), Sichuan Provincial Education Department Research (MPD stop cycle continuous flow of gas invasion transient wellbore, Grant no. 13ZB0189) and Features Leading Academic Discipline Project Funded Science Foundation Young Teacher (Whole process of underbalanced drilling wellbore flow model).

\section{References}

[1] M. Mohammadsalehi and N. Malekzadeh, "Optimization of hole cleaning and cutting removal in vertical, deviated and horizontal wells," in Proceedings of the SPE Asia Pacific Oil and Gas Conference and Exhibition, September 2011.

[2] S. Naganawa, A. Oikawa, Y. Masuda, T. Yonezawa, M. Hoshino, and P. Acuna, "Cuttings Transport in Directional and Horizontal Wells while Aerated Mud Drilling," in Proceedings of the IADC/SPE Asia Pacific Drilling Technology, September 2002.

[3] J. Paddock, S. Mustafiz, and M. R. Islam, "A new technique for cleaning horizontal wellbores," Petroleum Science and Technology, vol. 24, no. 7, pp. 807-819, 2006.

[4] X.-L. Guo, Z.-M. Wang, and Z.-H. Long, "Study on three-layer unsteady model of cuttings transport for extended-reach well," Journal of Petroleum Science and Engineering, vol. 73, no. 1-2, pp. 171-180, 2010.
[5] S. R. Shadizadeh and M. Zoveidavianpoor, "An experimental modeling of cuttings transport for an Iranian directional and horizontal well drilling," Petroleum Science and Technology, vol. 30, no. 8, pp. 786-799, 2012.

[6] Y. Li, N. Bjorndalen, and E. Kuru, "Numerical modelling of cuttings transport in horizontal wells using conventional drilling fluids," in Proceedings of the Canadian International Petroleum Conference, June 2004.

[7] D. J. Jerolmack and T. A. I. Brzinski, "Equivalence of abrupt grain-size transitions in alluvial rivers and eolian sand seas: a hypothesis," Geology, vol. 38, no. 8, pp. 719-722, 2010.

[8] A. J. Osho, W. Yan, and H. Yeung, "Experimental study of air-water flow in undulating pipeline and implication on sand transport," in Proceedings of the Offshore Technology Conference, May 2012.

[9] L. Zhou, "Hole cleaning during UBD in horizontal and inclined wellbore," in Proceedings of the IADC/SPE Drilling Conference, February 2006.

[10] Y. Zhang, Study on annular flow performance of coal-bed methane pinnate horizontal wells' under-balanced drilling [M.S. dissertation], China University of Petroleum, Beijing, China, 2008.

[11] G. H. Liu, T. Y. Song, and J. Li, "Analysis of cuttings transportation during drilling gas horizontal wells," Petroleum Drilling Techniques, vol. 37, no. 5, pp. 26-29, 2009.

[12] J. Wang, Z.-W. Wang, L.-X. Lu, Y. Zhu, and Y.-G. Wang, "Three-dimensional shock spectrum of critical component for nonlinear packaging system," Shock and Vibration, vol. 18, no. 3, pp. 437-445, 2011.

[13] Y. X. Dong and J. Ma, "Influence of total sand transport rates on the vertical distribution of different sand grain sizes in windsand flow on the coastal dune," Zhongshan Daxue Xuebao/Acta Scientiarum Natralium Universitatis Sunyatseni, vol. 48, no. 3, pp. 102-108, 2009.

[14] J. Wang, Y. Khan, R.-H. Yang, L.-X. Lu, Z.-W. Wang, and N. Faraz, "A mathematical modelling of inner-resonance of tangent nonlinear cushioning packaging system with critical components," Mathematical and Computer Modelling, vol. 54, no. 11-12, pp. 2573-2576, 2011.

[15] Z. Y. Yuan, Research on cuttings transport phenomenon with foam in annulus of horizontal wells [M.S. dissertation], China University of Petroleum, Beijing, China, 2009.

[16] L. P. Wan, N. Wei, Y. Meng, Y. J. Li, and G. Li, "The erosive energy analysis in annular gas drilling horizontal wells," Chinese Journal of Applied Mechanics, vol. 28, no. 3, pp. 266-269, 2011. 


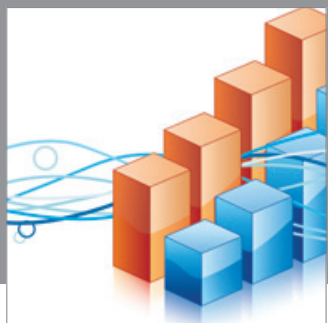

Advances in

Operations Research

mansans

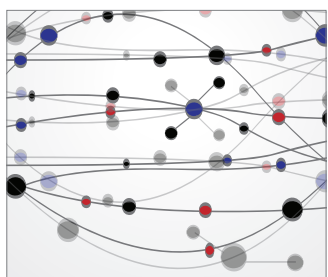

The Scientific World Journal
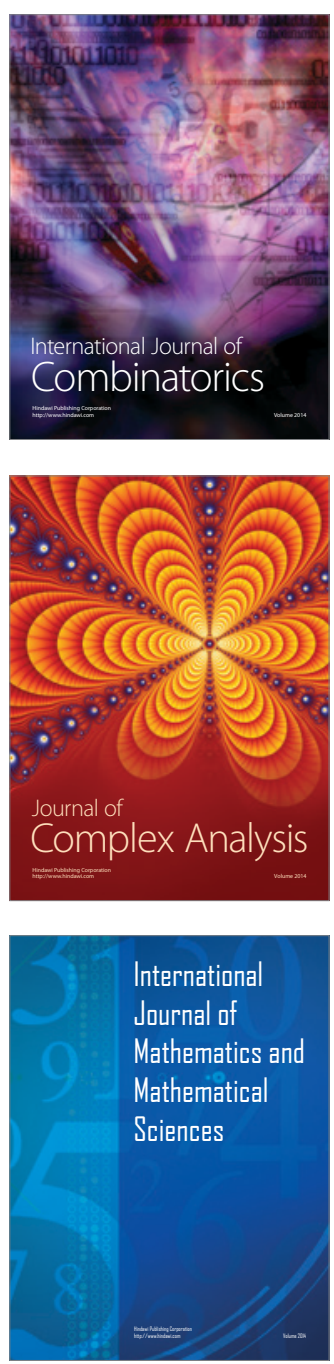
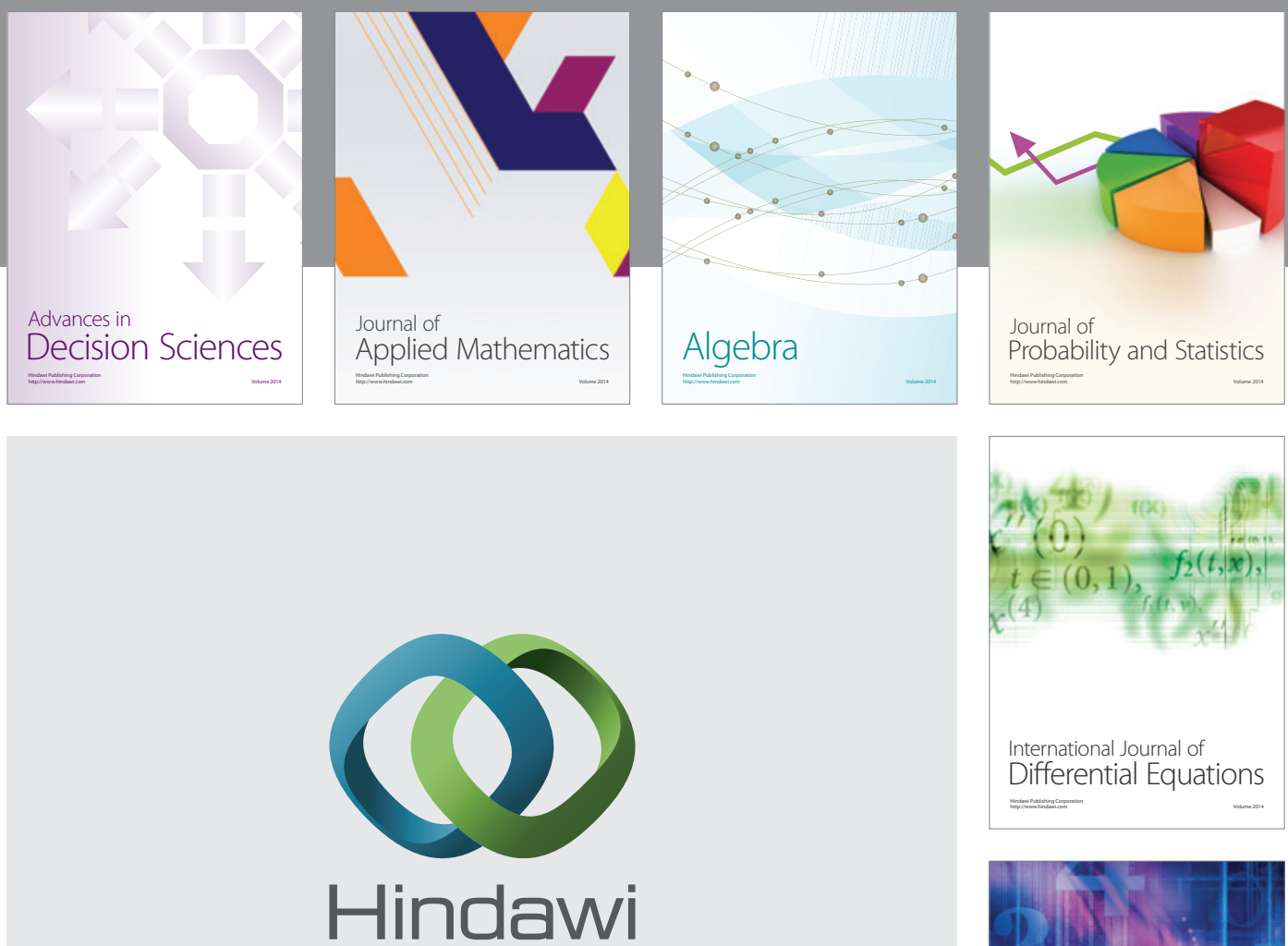

Submit your manuscripts at http://www.hindawi.com
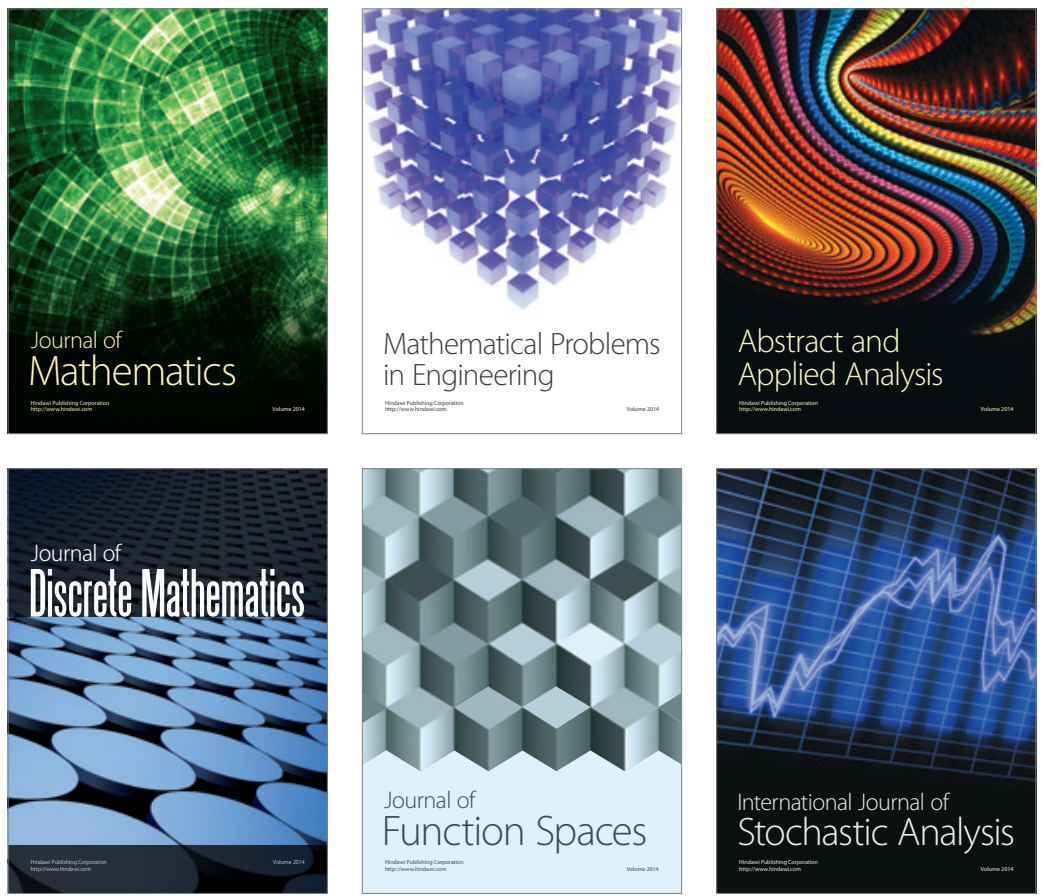

Journal of

Function Spaces

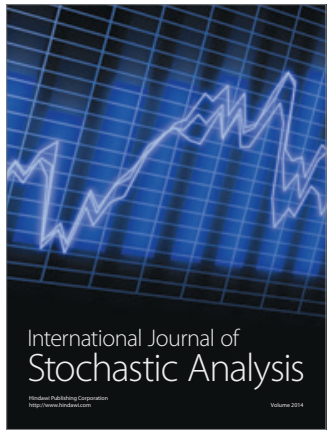

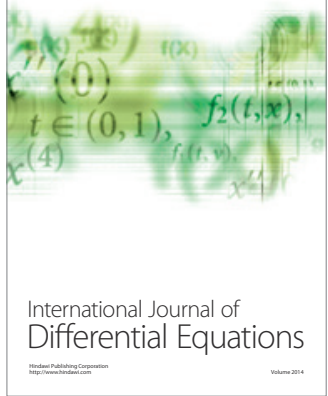
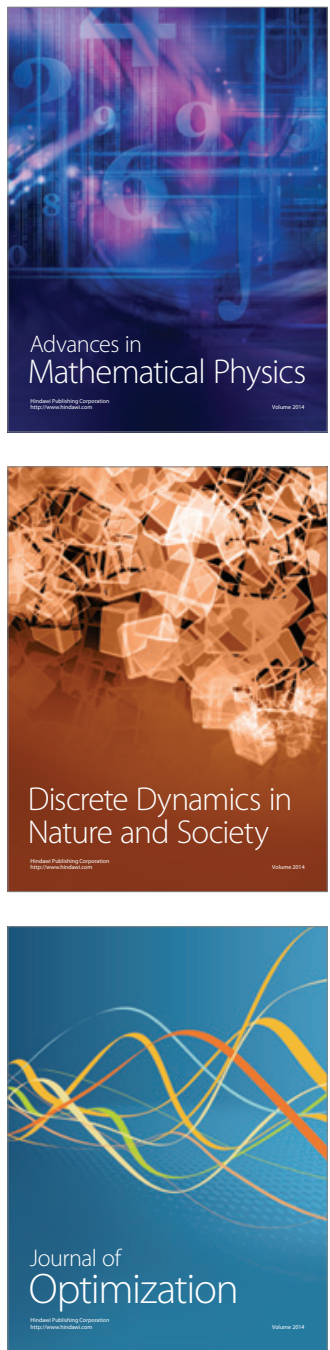